\title{
Masa abdominal en neonato atendido en zona de operaciones (Afganistán)
}

Bodega Quiroga I. ${ }^{1}$, Navarro Suay R. ${ }^{2}$, Sáenz Casco L. ${ }^{3}$, Tamburri Bariain R. ${ }^{4}$, Campillo Laguna JR. ${ }^{5}$

Sanid. mil. 2014; 70 (2): 213-214; ISSN: 1887-8571

\section{CASO CLÍNICO}

Varón afgano de 15 días de vida $(2,9 \mathrm{~kg}$ de peso y $47 \mathrm{~cm}$ de estatura), valorado en el Role 2E español de Herat (Afganistán) por un cuadro de distensión abdominal acompañado de 2 a 3 vómitos al día de escasa cuantía y deposiciones de aspecto normal.

En la exploración se observaba un abdomen distendido (Figura 1) y se palpaba una masa que ocupaba el hipocondrio iz-

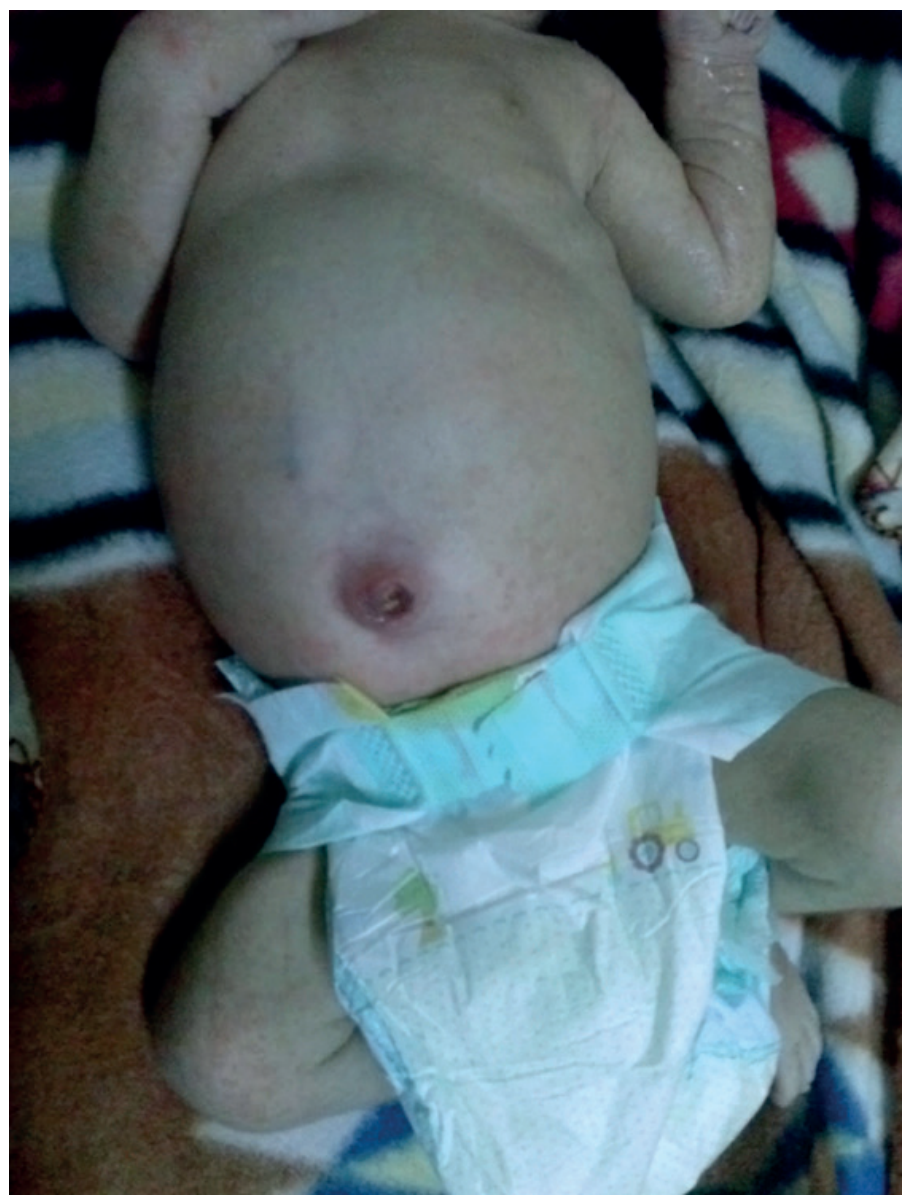

Figura 1. Imagen del abdomen.

${ }^{1}$ Cte. Médico. Servicio de Cirugía General y del Aparato Digestivo.

2 Cte. Médico. Servicio de Anestesiología, Reanimación y Terapéutica del Dolor.

3 Cte. Médico. Servicio de Medicina Intensiva.

${ }^{4}$ Cte. Médico. Servicio de Cirugía Ortopédica y Traumatología.

5 Tcol. Médico. Servicio de Telemedicina.

Hospital Central de la Defensa Gómez Ulla. Madrid. España.

Recibido: 25 de abril de 2014

Aceptado: 10 de junio de 2014 quierdo y el mesogastrio. Se consultó por Telemedicinaa con los Servicios de Pediatría y Cirugía Pediátrica del Hospital Central de la Defensa "Gómez Ulla".

Desde este Centro se aconsejó la realización de un estudio gastroduodenal (EGD) con gastrografin ${ }^{\circledR}$ y una ecografía abdominal.

En el EGD se apreciaba el paso de contraste a duodeno y una zona de "silencio radiológico" en hemiabdomen izquierdo, con desplazamiento de asas de intestino delgado (Figura 2). La ecografía teleguiada mostró una masa heterogénea de aproximadamente $5 \mathrm{~cm}$.

La sospecha diagnóstica inicial de la masa fue que se tratara de un neuroblastoma, sin poder descartar otras posibilidades.

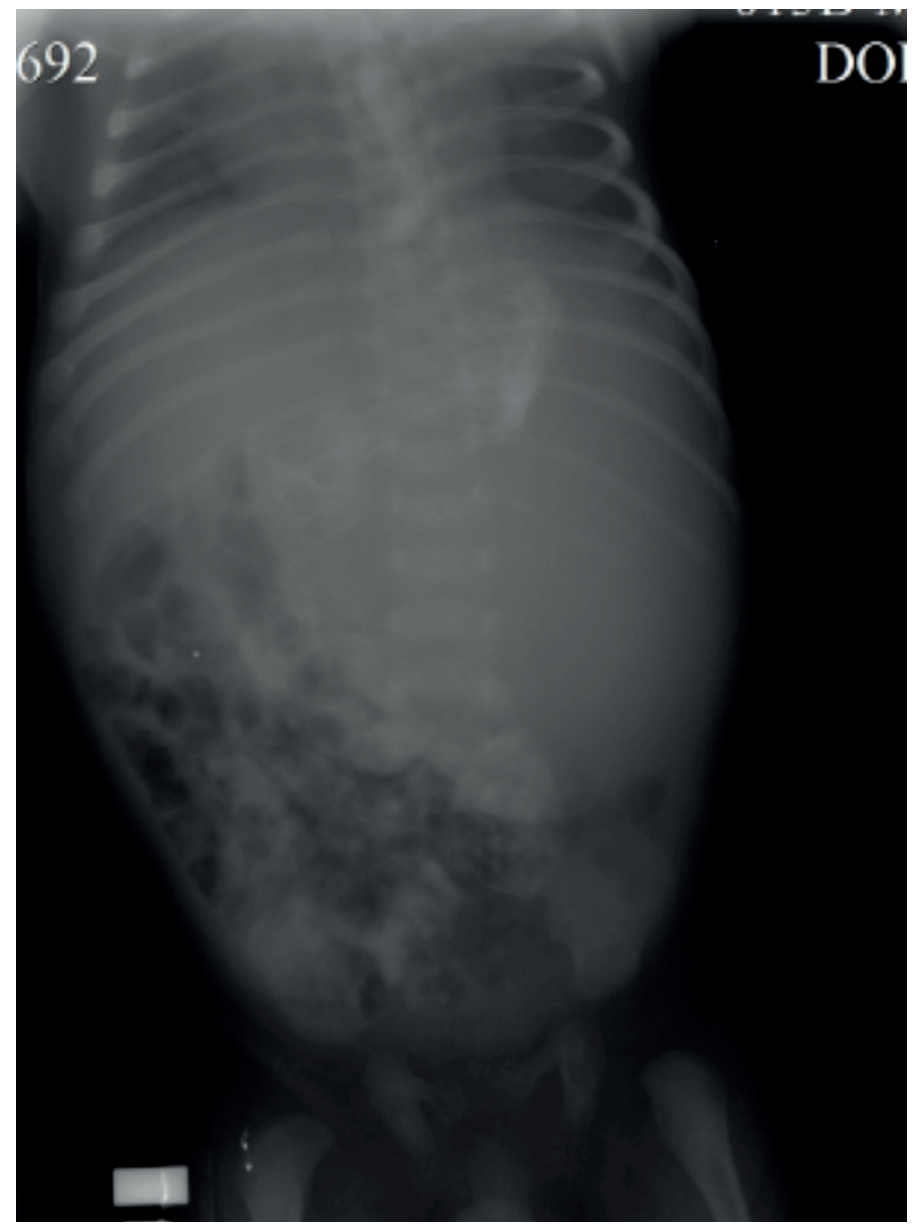

Figura 2. EGD con gastrografin. 


\section{Diagnóstico radiológico: Hepatoblastoma}

Entre los tumores más frecuentes en la época neonatal se encuentran el neuroblastoma, el teratoma y el tumor de Wilms. En este caso, la sospecha clínica inicial se orientó hacia un neuroblastoma tras la exploración física y las pruebas complementarias inicales. Este tumor sólido extracraneal, derivado de las células de la cresta neural, es el más frecuente en este grupo de edad y la médula adrenal es su localización más típica ${ }^{1}$.

Se realizó una nueva consulta por Telemedicina a los Servicios de Radiología del Hospital Central de la Defensa y del Hospital San Juan de Dios de Barcelona. Se indicó la realización de una TC abdominal (Figura 3) dado que en Zona de Operaciones no se dispone de Resonancia Magnética. El diagnóstico radiológico fue de hepatoblastoma.

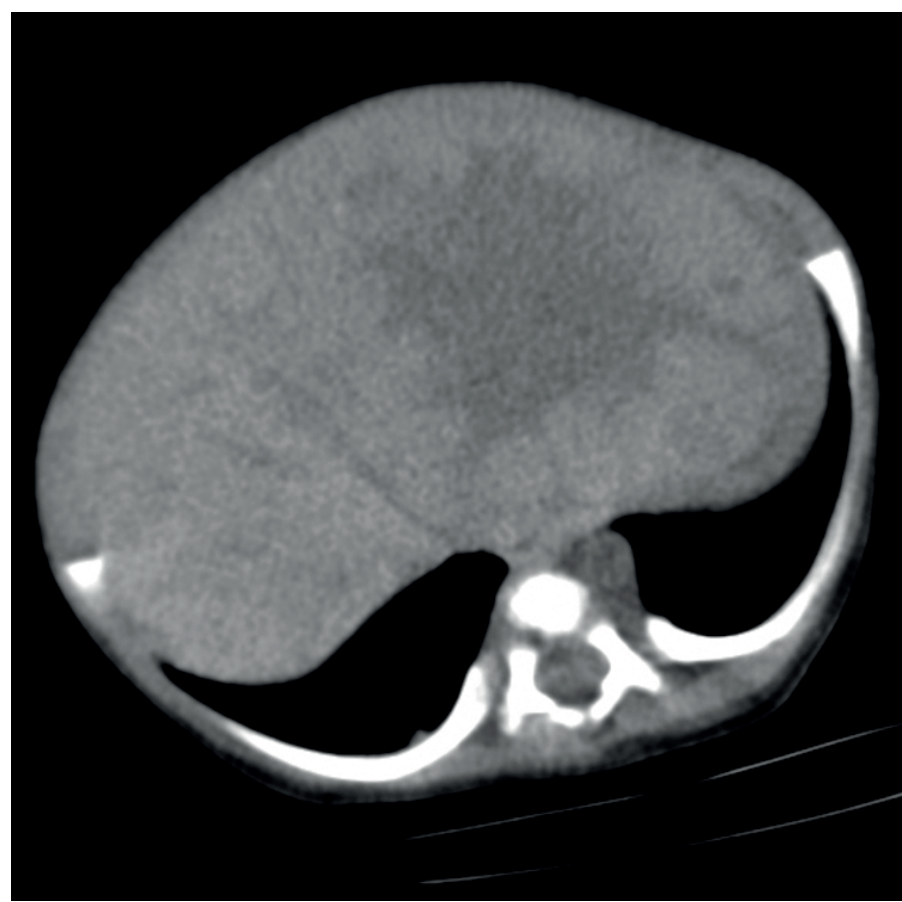

Figura 3. TC abdominal.
Los tumores hepáticos en neonatos suelen presentarse como masas asintomáticas. Pueden ser benignos (hemangiomas, hamartomas o endoteliomas), malignos o metástasis, generalmente de un neuroblastoma. El hepatoblastoma congénito es el tumor maligno hepático más frecuente, suele tener elevación de la alfafetoproteína y su tratamiento incluye quimioterapia adyuvante con intención citorreductora y cirugía posterior; puede estar indicado el trasplante hepático².

La presencia de equipos normalizados de telemedicina en los primeros escalones sanitarios desplegados en las diferentes zonas de operaciones ayudan al diagnóstico y tratamiento de pacientes afectos de patologías no frecuentes en territorio nacional o que son difícilmente evaluadas por médicos no especialistas en diversas áreas como es la pediatría $a^{3-5}$.

\section{BIBLIOGRAFÍA}

1. Fisher JP1, Tweddle DA.Neonatal neuroblastoma.Semin Fetal Neonatal Med. 2012;17(4):207-15.

2. Orbach D1, Sarnacki S, Brisse HJ, Gauthier-Villars M, Jarreau PH, Tsatsaris V et al.Neonatal cancer.LancetOncol. 2013; 14(13): 609-20.

3. Martínez-Ramos C. Telemedicina en España: Comunidades Autónomas, Sanidad Militar, Marítima y Penitenciaria. Proyectos humanitarios. Serie Medicina Recursos Educativos 2009; 1(1): 182-202.

4. Fuenfer MM, Creamer KM. PediatricSurgery and medicine for hostile environments.Washington: BorderInstitute; 2010.

5. García-Cubillana JM, Samalea F. El pediatra en las misiones de ayuda humanitaria. Vox paediatrica 2006; 14(1): 7-12. 